\title{
Role of Cartilage as a Graft Material for Tympanic Membrane and in Middle Ear Reconstruction
}

\author{
Anant Chouhan*, Bhuvnesh Kumar Singh, Praveen Chandra Verma \\ Department of ENT, JLN Medical College, Ajmer, India \\ Email: ${ }^{*}$ dr.apschouhan@gmail.com
}

Received 30 January 2015; accepted 23 February 2015; published 28 February 2015

Copyright (C) 2015 by authors and Scientific Research Publishing Inc.

This work is licensed under the Creative Commons Attribution International License (CC BY). http://creativecommons.org/licenses/by/4.0/

(c) (i) Open Access

\section{Abstract}

Objective: The work was planned to evaluate the results of cartilage graft in the surgical treatment of chronic suppurative otitis media. Study Design: A prospective study. Materials and Methods: The present study was a prospective study of tympanoplasties and tympanomastoid surgeries performed on 100 patients. The main outcome measures were both anatomical and functional in form of graft incorporation and postoperative hearing function. Results: Cartilage was used as tympanic membrane and/or ossicle graft in the cases. There were no immediate postoperative or long term complications of surgery except for 10 cases in which there was a failure of graft uptake. There was a 7.6-decibel (dB) improvement in mean air conduction threshold post-operatively. A mean closure of average air bone gap of 8.4 decibels (dB) was noted which was statistically significant. Conclusion: The cartilage graft is a very effective option for the repair of the conducting mechanism of the ear with good take-up rates, less chances of rejection or extrusion and very few significant complications. The thickness of cartilage creates stiffness that is more resistant than the fascia to the anatomic deformities caused by negative middle ear pressure thus improving the long term integrity of the graft.

\section{Keywords}

Cartilage Graft, Pure Tone Audiometry, Air Bone Gap

\section{Introduction}

A dry and intact hearing apparatus is an essential prerequisite for normal hearing. In our clinical practice, we

\footnotetext{
${ }^{*}$ Corresponding author.
}

How to cite this paper: Chouhan, A., Singh, B.K. and Verma, P.C. (2015) Role of Cartilage as a Graft Material for Tympanic Membrane and in Middle Ear Reconstruction. International Journal of Otolaryngology and Head \& Neck Surgery, 4, 66-72. 
encounter a great deal of patients suffering from chronic suppurative otitis media (CSOM) leading to tympanic membrane perforations, retractions, atelectasis and cholesteatoma. Each of these conditions has a deleterious effect on some part of the sound conducting mechanism.

Cartilage is a reliable graft for tympanic membrane reconstruction [1]. Most frequently used grafting material is temporal fascia graft due to the ease of its accessibility at the surgical site. However, in situations such as advanced middle ear pathology, large perforations, atelectatic ears or retraction pockets, temporalis fascia may cause higher failure rates regardless of the surgical technique used [2] [3].

The earliest reconstructive surgeries of the hearing apparatus were tried in the $16^{\text {th }}$ century. "Tympanoplasty" has been defined by the American Academy of Ophthalmology and Otolaryngology Subcommittee on Conservation of Hearing [4] as "A procedure to eradicate disease in the middle ear and to reconstruct the hearing mechanism, with or without tympanic membrane grafting."

The long term aim of middle ear reconstruction is to reconstruct the tympanic membrane and the sound conducting mechanism and to keep the ear dry. Since the introduction of tympanoplasty, in the fifties, by Zollner [5] and Wullstein [6] various graft materials and perforation closure techniques have been described since then such as temporal fascia [7], perichondrium [8], periosteum [9], vein [10], duramater [11] and cartilage [12] [13]. Cartilage is preferred because of its increased stability and resistance to middle ear pressure even in cases with chronic eustachian tube dysfunction. Utech, in 1959, first introduced cartilage in middle ear surgery [14]. The technique was then promoted by Prof. Heermann J. from Essen, Germany, who used "the cartilage palisade technique" for the reconstruction of the TM and the auditory canal wall [15] [16]. The mechanical characteristics of cartilage offer the advantage of high resistance to retraction and re-perforation. Cartilage has a constant shape, firmer than fascia and also lacks fibrous tissue, so that the post-operative dimensions remain the same and it is also nourished by diffusion and shows great adaptation with tympanic membrane [1].

\section{Objective}

The work was planned to evaluate the results of cartilage graft in the surgical treatment of chronic suppurative otitis media.

\section{Material \& Methods}

The present study "Role of Cartilage as a Graft Material for Tympanic Membrane and in Middle Ear Reconstruction” was conducted in the Department of Otorhinolaryngology and Head \& Neck Surgery of JLN Medical College \& Hospital, Ajmer from August 2011 to December 2013.

Study design: prospective study.

Study population: inclusion criteria:

1) Tubotympanic type of CSOM in the quiescent stage that included occasional wet ears.

2) Patients of active CSOM, tubotympanic type not improving with conservative treatment that included persistent wet ears.

3) Patients with retraction pocket and conductive hearing loss.

4) Patients of CSOM atticoantral type where cartilage would be kept for ossiculoplasty and mastoid cavity reconstruction.

Exclusion criteria:

1) Patients of tubotympanic CSOM having septic foci in nose and throat. Such patients were considered after elimination of the septic foci medically and/or surgically.

2) Patients of atticoantral CSOM where cartilage was not used for reconstruction after mastoidectomy.

Sample size: 100 .

All patients had undergone thorough history taking and complete ear, nose and throat (ENT) examination including tuning fork tests. A battery of investigations including routine blood investigations, urine examination, $\mathrm{X}$-ray mastoid (lateral oblique view), X-ray chest (posteroanterior view), electrocardiogram, audiometry, tuning fork tests and examination under microscope was done in all patients. Pus for culture and sensitivity, tympanometry, High Resolution Computed Tomography (HRCT) scan temporal bone were done in some cases. Preanaesthetic check up was done and after anaesthetic fitness patients were posted for surgery.

Anaesthesia: general/local.

Technique of surgery: 
The surgical areas were cleaned with povidine iodine $0.5 \%$ and $70 \%$ methylated spirit. $2 \%$ lidocaine with 1:200,000 adrenaline solution was infiltrated locally.

Post-aural Wilde's incision was made in majority of the patients. Posterior tympanomeatal flap was elevated up to the fibrous annulus which was detached from the bony annulus and positioned anteriorly thus exposing the middle ear. Status of the middle ear structures was then assessed to decide the type of tympanoplasty and size and shape of cartilage graft required. Conchal or tragal cartilage used as autograft. Mastoidectomy either cortical or canal wall down mastoidectomy was done as per the requirement. Then ossicular chain was checked.

If the ossicular chain was intact than type I tympanoplasty via underlay technique was done using cartilage of $1 \mathrm{~mm}$ thickness made by cartilage slicer. If there was necrosis of the incus, than cartilage was reshaped and kept over stapes head and malleus in type II tympanoplasty. In patients with cholesteatoma, canal wall down mastoidectomy was done and cartilage was used for reconstruction. Gel foam was kept in middle ear to stabilize the graft in position. The posterior tympanomeatal flap was then repositioned back and canal wall filled with gel foam.

Closure was done in two layers (subcutaneous and skin). Mastoid dressing was given for 7 days. Total suture removal was done at 7 postoperative day. Patients were given antibiotic cover for 3 weeks.

Follow up was done at 1 month, 6 weeks and 3 months. At each follow up the complaints of the patients were noted. Microscopic examination was done to see the condition of the canal and the graft. Pure tone audiometry was done at $3^{\text {rd }}$ month of follow up. Graft uptake was considered as successful if there was no residual perforation on follow up at 3 months. Hearing results were compared using the guidelines recommended by Committee on Hearing and Equilibrium of the American Academy of Otolaryngology-Head and Neck Surgery for the evaluation of results for conductive hearing loss [17]. This includes reporting of the mean, standard deviation and range of the postoperative air bone gap. Statistical analysis of these results was done by using paired " $\mathrm{t}$ " test.

\section{Results}

54 patients were residing in rural communities while the rest 46 belonged to urban areas. Out of the 100 studied cases 54 subjects were operated on the right ear while 46 were operated on left ear.

The age of the patients included in the study ranged from 14 years to 52 years with mean age of presentation of $27.8 \pm 10.8$ years. The commonest age group was 21 - 30 years having 38 patients followed by $<20$ years age group having 28 patients, 41 - 50 years age group having 10 patients, $>50$ years age group having 4 patients. In the current study, there were 54 males (54\%) and 46 females (46\%). Slight male preponderance was recorded (Table 1).

The commonest complaint of patients was ear discharge, seen in $100 \%$ of the patients including occasional or persistent wet ears. Second common presenting complaint was hearing impairment which was seen in $88 \%$ of patients. There was associated earache in $24 \%$ patients and $4 \%$ of patients had tinnitus and vertigo each in the present study.

Pre-operative hearing assessment was done using pure tone audiometry. Out of the 100 studied cases, 42 patients had air conduction level between 21 to 30 decibels. 20 patients had air conduction level between 41 - 50 decibels followed by 31 - 40 decibels in 14 patients and 12 patients had air conduction level above 50 decibels. 12 subjects had air conduction level below or equal to 20 decibels.

In present study, out of 100 patients, 66 patients had bone conduction level between 5 to $10 \mathrm{~dB}$ and 18 patients had air conduction level $\leq 5 \mathrm{~dB} .12$ patients had bone conduction level between 11 to $15 \mathrm{~dB}$ followed by 2 patients 16 to $20 \mathrm{~dB}$ and 2 above $20 \mathrm{~dB}$.

Table 1. Age and sex distribution of patients.

\begin{tabular}{|c|c|c|c|c|}
\hline \multirow{2}{*}{ Age group } & \multicolumn{2}{|c|}{ Number of patients } & \multicolumn{2}{|c|}{ Percentage } \\
\hline & Male & Female & Male & Female \\
\hline$<20$ & 15 & 13 & $15 \%$ & $13 \%$ \\
\hline $21-30$ & 20 & 18 & $20 \%$ & $18 \%$ \\
\hline $31-40$ & 10 & 10 & $10 \%$ & $10 \%$ \\
\hline $41-50$ & 6 & 4 & $6 \%$ & $4 \%$ \\
\hline$>50$ & 3 & 1 & $3 \%$ & $1 \%$ \\
\hline
\end{tabular}


In present study most of the patients (48) had air bone gap between 16 to 25 decibels. 30 patients had air bone gap between 60 - 40 decibels and 14 patients had $\leq 15$ decibels.

Pre-operatively mean air conduction was $35 \mathrm{~dB}$ with standard deviation of $12 \mathrm{~dB}$. Mean bone conduction was 8.76 with standard deviation of $3.8 \mathrm{~dB}$ and mean air bone gap was $26.4 \mathrm{~dB}$ with standard deviation of $10 \mathrm{~dB}$ (Table 2).

This table shows that most common intra-operative finding was central perforation which was seen $46 \%$ patients. Most commonly involved ossicle was incus, involved in $62 \%$ patients followed by stapes in $36 \%$ patients. Malleus was involved only in $4 \%$ patients (Table 3 ).

In the present study, type I tympanoplasty was carried out in 36 cases. Type II tympanoplasty was performed in 28 patients and type III tympanoplasty in 36 patients. Mastoidectomy was performed in 76 patients. Mastoidectomy was done in cases of tympanic membrane (TM) retraction, cholesteatoma and granulations. 40 patients underwent modified intact canal wall mastoidectomy, out of which type II tympanoplasty was done in 28 and type I in rest 12 cases. In 36 cases canal wall down mastoidectomy with type III tympanoplasty was done.

Successful graft uptake was achieved in $90 \%$ of the 100 operated ears. In $10 \%$ residual perforation was seen at the end of 3 months study period.

Post-operatively out of 100 studied cases, 44 patients had air conduction level below or equal to 20 decibels. 22 patients had air conduction level between 21 - 30 decibels and 18 patients had between 41 - 50 decibels followed by 16 patients between 31 - 40 decibels.

Out of 100 patients, 66 patients had bone conduction level between 6 to $10 \mathrm{~dB}$. 16 patients had bone conduction level $\leq 5 \mathrm{~dB}$ and 10 patients had between 11 to $15 \mathrm{~dB}$. 6 patients had bone conduction level between $16-20$ $\mathrm{dB}$ and only 2 patients had more than $20 \mathrm{~dB}$.

Post-operative hearing assessment was done using the same parameters as those used for preoperative hearing assessment. Post-operatively 56 patients had air bone gap $\leq 15 \mathrm{~dB}$ and 30 patients had between $26-40 \mathrm{~dB}$ followed by 14 patients between $16-25 \mathrm{~dB}$. The AB Gap in 10 cases of graft failure was $>25 \mathrm{~dB}$.

Post-operatively mean air conduction was $27.4 \mathrm{~dB}$ with standard deviation of $11.5 \mathrm{~dB}$. Mean bone conduction was 9.26 with standard deviation of $4.03 \mathrm{~dB}$ and mean air bone gap was $18 \mathrm{~dB}$ with standard deviation of $9 \mathrm{~dB}$ (Table 4).

On comparison of pre-operative and post-operative hearing results there was a mean improvement in air conduction threshold by $7.6 \mathrm{~dB}$. On applying " $\mathrm{t}$ " test it showed that this difference was highly significant $(P$ value $=$ 0.0017) thus verifying the efficacy of cartilage graft in restoring the distorted sound conduction mechanism of

Table 2. Pre-operative audiometric evaluation.

\begin{tabular}{cccc}
\hline Type of hearing loss & Range (in dB) & Mean (in dB) & SD (in dB) \\
\hline Air conduction & $15-60$ & 35 & 12 \\
Bone conduction & $5-25$ & 8.76 & 3.8 \\
Air bone gap & $5-44$ & 26.4 & 10 \\
\hline
\end{tabular}

Table 3. Intra-operative findings.

\begin{tabular}{ccc}
\hline Intra operative findings & No. of patients & Percentage \\
\hline Central perforation & 46 & $46 \%$ \\
Marginal & 30 & $30 \%$ \\
Posterosuperior retraction & 22 & $32 \%$ \\
Cholesteatoma & 36 & $36 \%$ \\
Plastered tympanic membrane & 6 & $10 \%$ \\
Tympanosclerotic plaque & 10 & $4 \%$ \\
Malleus necrosed & 4 & $62 \%$ \\
Incus necrosed & $36 \%$ \\
Stapes erosion & $36 \%$ \\
\hline
\end{tabular}


the ear. However, as can be expected there was no significant change in bone conduction thresholds $(P$ value $=$ 0.52). On analysing the audiometric parameter of air-bone gap by the same paired "t" test there was again significant improvement in air-bone gap $(8.4 \mathrm{~dB})$ after surgery $(P$ value $=0.00003)$ (Table 5$)$.

\section{Discussion}

Cartilage is a reliable graft for tympanic membrane reconstruction as it is nourished by diffusion and becomes well incorporated in the tympanic membrane [1].

The demographic and clinical data was collected which included age, sex, rural/urban population, diagnosis (chronic suppurative otitis media with or without cholesteatoma), prior otologic surgery, details of surgical technique, intra-operative findings (middle ear mucosa status, ossicular chain status, and reconstruction), post-operative findings (graft incorporation), hearing and duration of follow-up. The main outcome measures were both anatomical and functional in form of graft incorporation and postoperative hearing function.

In the present study, successful graft uptake was achieved in 90 ears (90\%) of the 100 ears operated. In 10 ears $(10 \%)$ residual perforation was seen at the end of the study period. These results are comparable to the study by Sapci T et al. [18] in which 92\% successful closure of tympanic membrane was achieved using tragal cartilage graft.

Results of tympanic membrane closure achieved by cartilage graft are comparable to those achieved by different workers for temporalis fascia graft-Dabholkar JP et al. [19] (84\% graft uptake), Ozbek C et al. [20] (70.2\%), Sirena E et al. [21] (80\%), Yetiser S et al. [22] (95\%).

Results of graft uptake in the present study are more or less better than those which have been achieved by the use of other graft materials like tragal perichondrium-Dabholkar JP et al. [19] (80\% success rate), skin graft by Wright WK [23] (74\% success) and tympanic membrane homograft by Marquet JFE [24] (80\% success rate).

The thickness of cartilage creates stiffness that is more resistant than the fascia to the anatomic deformities caused by negative middle ear pressure thus improving the long term integrity of the graft.

In present study, the mean air conduction preoperatively was 35 decibels which improved to 27.4 decibels post-operatively. The mean pre-operative bone conduction was 8.76 decibels as compared to mean postoperative bone conduction of 9.26 decibels. The mean air bone gap pre-operative was 26.4 decibels which was reduced to 18 decibels post-operatively thus giving improvement in hearing of 8.4 decibels.

These results are comparable to the study done by Mahadevaiah A et al. [25] in which they achieved difference of mean pre- and post-surgery air bone gap of 13 decibels.

Factors which predicted the success rate of the middle ear reconstruction include occasionally/persistently wet ear, ossicular status, mobility/fixity of ossicular chain, pathology including cholesteatoma/granulations, type of surgery performed and nutritional status, smoking that definitely have role in healing.

There was no immediate postoperative or long term complications of surgery except for 10 cases in which there was failure of graft uptake.

A potential drawback of cartilage graft was the graft opacity, as it may be more difficult to detect eventual residual/recurrent cholesteatoma.

Table 4. Post-operative audiometric evaluation.

\begin{tabular}{cccc}
\hline Type of hearing loss & Range (in dB) & Mean (in dB) & SD (in dB) \\
\hline Air conduction & $10-48$ & 27.4 & 11.5 \\
Bone conduction & $5-25$ & 9.26 & 4.03 \\
Air bone gap & $4-38$ & 18 & 9 \\
\hline
\end{tabular}

Table 5. Comparison of pre- and post-operative hearing results.

\begin{tabular}{cccc}
\hline Hearing results & Pre-operative (mean \pm S.D.) & Post-operative (mean \pm S.D.) & $P$ value \\
Air conduction & $35 \pm 12$ & $27.4 \pm 11.5$ & 0.0017 \\
Bone conduction & $8.76 \pm 3.8$ & $9.26 \pm 4.03$ & 0.5248 \\
A-B gap & $26.4 \pm 10$ & $18 \pm 9$ & 0.00003 \\
\hline
\end{tabular}




\section{Conclusions}

The cartilage graft is a very effective option for the repair of the conducting mechanism of the ear with good take-up rates, less chances of rejection or extrusion and very few significant complications.

- There was a 7.6-dB improvement in mean air conduction threshold post-operatively which was statistically significant ( $P$ value 0.0017$)$.

- There was no significant improvement in the bone conduction threshold. This was as per expectations as the surgery was aimed to reconstruct the conduction mechanism only.

- A mean closure of average air bone gap of $8.4 \mathrm{~dB}$ was noted. This is also statistically significant ( $P$ value 0.00003 ) as derived by applying the paired "t" test.

- Cartilage is an effective autologous graft for the reconstruction of the conduction mechanism of ear. Thus we conclude that cartilage is an effective graft material for middle ear reconstruction.

- The results of cartilage in middle ear reconstruction are comparable to that of other graft materials as reported in literature.

\section{Conflict of Interest}

None.

\section{References}

[1] Levinson, R.M. (1987) Cartilage-Perichondrial Composite Graft Tympanoplasty in the Treatment of Posterior Marginal and Attic Retraction Pockets. Laryngoscope, 97, 1069-1074. http://dx.doi.org/10.1288/00005537-198709000-00013

[2] Buckingham, R.A. (1992) Fascia and Perichondrium Atrophy in Tympanoplasty and Recurrent Middle Ear Atelectasis. Annals of Otology, Rhinology Laryngology, 101, 755-758. http://dx.doi.org/10.1177/000348949210100907

[3] Milewski, C. (1993) Composite Graft Tympanoplasty in the Treatment of Ears with Advanced Middle Ear Pathology. Laryngoscope, 103, 1352-1356. http://dx.doi.org/10.1288/00005537-199312000-00006

[4] Committee on Conservation of Hearing of the American Academy of Ophthalmology and Otolaryngology (1964) Standard Classification for Surgery of Chronic Ear Disease. Archives of Otolaryngology-Head and Neck Surgery, 81, 204-205.

[5] Zollner, F. (1955) The Principles of Plastic Surgery of the Sound Conducting Apparatus. Journal of Laryngology and Otology, 69, 637-652. http://dx.doi.org/10.1017/S0022215100051240

[6] Wullstein, H.L. (1952) Functional Operation in the Middle Ear with Split Thickness Skin Graft. Archives of Otorhinolaryngology, 161, 422-436. http://dx.doi.org/10.1007/BF02129204

[7] Heermann, H. (1960) Tympanic Membrane Plastic Repair with Temporalis Fascia. Hals Nas Ohrenh, 9, $136-139$.

[8] Salen, B. (1968) Tympanic Membrane Grafts of Full Thickness Skin, Fascia and Cartilage with Its Perichondrium, an Experimental and Clinical Investigation. Acta Oto-Laryngologica, 244, 5-73.

[9] Bocca, E., Cis, C. and Zernotti, E. (1959) L’impiego di lembi liberi di periostio nella tympanoplastica. Archivio Italiano di Otologia, Rinologia e Laringologia. Supplemento, 40, 205.

[10] Tabb, H.G. (1960) Closure of Perforation of the Tympanic Membrane by Vein Grafts: A Preliminary Report of 20 Cases. Laryngoscope, 70, 271-274. http://dx.doi.org/10.1288/00005537-196003000-00004

[11] Albrite, J.P. and Leigh, B.G. (1966) Dural Homograft (Alloplastic) Myringoplasty. The Laryngoscope, 76, $1687-1693$. http://dx.doi.org/10.1288/00005537-196610000-00006

[12] Jansen, C. (1963) Cartilage-Tympanoplasty. The Laryngoscope, 73, 1288-1302. http://dx.doi.org/10.1288/00005537-196310000-00006

[13] Salen, B. (1963) Myringoplasty Using Septum Cartilage. Acta Otolaryngologica, 57, 82-91.

[14] Utech, H. (1959) Ueber diagnostische und therapeutische Moeglichkeiten der Tympanotomie bei Schalleitungsstoerungen. Zeitschrift für Laryngologie, Rhinologie, Otologie und ihre Grenzgebiete, 38, 212-221.

[15] Heermann, J. (1978) Auricular Cartilage Palisade Tympano-, Epitympano-, Antrum- and Mastoid-Plastics. Clinical Otolaryngology \& Allied Sciences, 3, 443-446. http://dx.doi.org/10.1111/j.1365-2273.1978.tb00726.x

[16] Heermann, J. (1992) Autograft Tragal and Conchal Palisade Cartilage and Perichondrium in Tympanomastoid Reconstruction. Ear, Nose \& Throat Journal, 71, 344-349.

[17] Guidelines of the Committee on the Hearing and Equilibrium (1995) Committee in Hearing and Evaluation of Results 
of Treatment of Conductive Hearing Loss. Otolaryngology—Head and Neck Surgery, 106, 865-867.

[18] Sapci, T., Almac, S., Usta, C., Karavas, A., Mercangoz, C. and Evimik, M.F. (2006) Comparison between Tympanoplasties with Cartilage Perichondrium Composite Graft and Temporal Fascia Graft in Terms of Hearing Levels and Healing. Kulak Burun Boğaz Ihtisas Dergisi, 16, 255-260.

[19] Dabholkar, J.P., Vora, K. and Sikdar, A. (2007) Comparative Study of Underlay Tympanoplasty with Temporalis Fascia and Tragal Perichondrium. Indian Journal of Otolaryngology and Head \& Neck Surgery, 59, 116-119. http://dx.doi.org/10.1007/s12070-007-0035-0

[20] Ozbek, C., Cifta, O., Tuna, E.E., Yazkan, O. and Ozdem, C. (2008) A Comparison of Cartilage Palisades and Fascia in Type I Tympanoplasty in Children: Anatomic and Functional Results. Otology \& Neurotology, 29, 679-683. http://dx.doi.org/10.1097/MAO.0b013e31817dad57

[21] Sirena, E., Carvalho, B., Buschle, M. and Mocellin, M. (2010) Timpanoplastia Myringoplasty Type 1 and in Residency Surgical Results and Audiometric. International Archives of Otorhinolaryngology, 14, 60-65.

[22] Yetiser, S. and Hidin, Y. (2009) Temporalis Fascia and Cartilage Perichondrium Composite Shield Graft for Reconstruction for Tympanic Membrane. The Annals of Otology, Rhinology, and Laryngology, 118, 570-574.

[23] Wright, W.K. (1956) Repair of Chronic Central Perforation of Tympanic Membrane by Skin Grafting. The Laryngoscope, 66, 1464-1487. http://dx.doi.org/10.1002/lary.5540661104

[24] Marquet, J.F.E. (1968) Myringoplasty by Eardrum Transplantation. The Laryngoscope, 78, 1329-1336. http://dx.doi.org/10.1288/00005537-196808000-00006

[25] Mahadeviah, A. and Parikh, B. (2008) Modified Intact Canal Wall Mastoidectomy: Long Term Hearing Results in Hearing and Healing. Indian Journal of Otolaryngology and Head \& Neck Surgery, 60, 317-323. http://dx.doi.org/10.1007/s12070-008-0109-7 
Scientific Research Publishing (SCIRP) is one of the largest Open Access journal publishers. It is currently publishing more than 200 open access, online, peer-reviewed journals covering a wide range of academic disciplines. SCIRP serves the worldwide academic communities and contributes to the progress and application of science with its publication.

Other selected journals from SCIRP are listed as below. Submit your manuscript to us via either submit@scirp.org or Online Submission Portal.
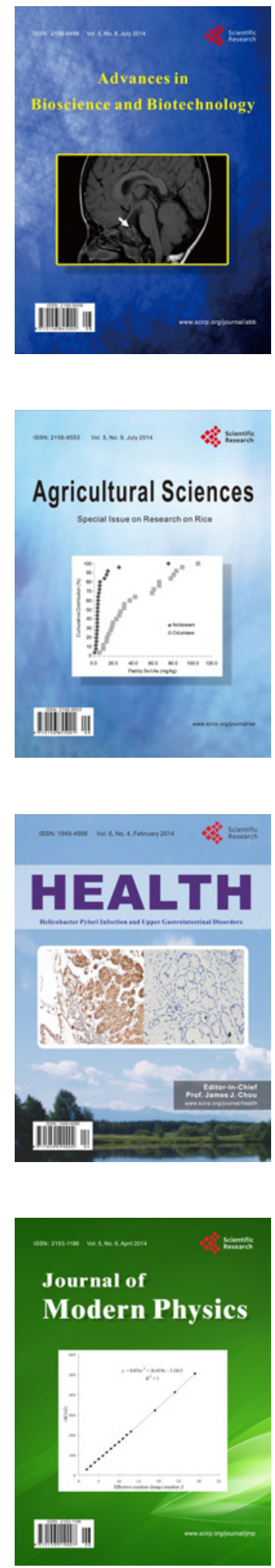
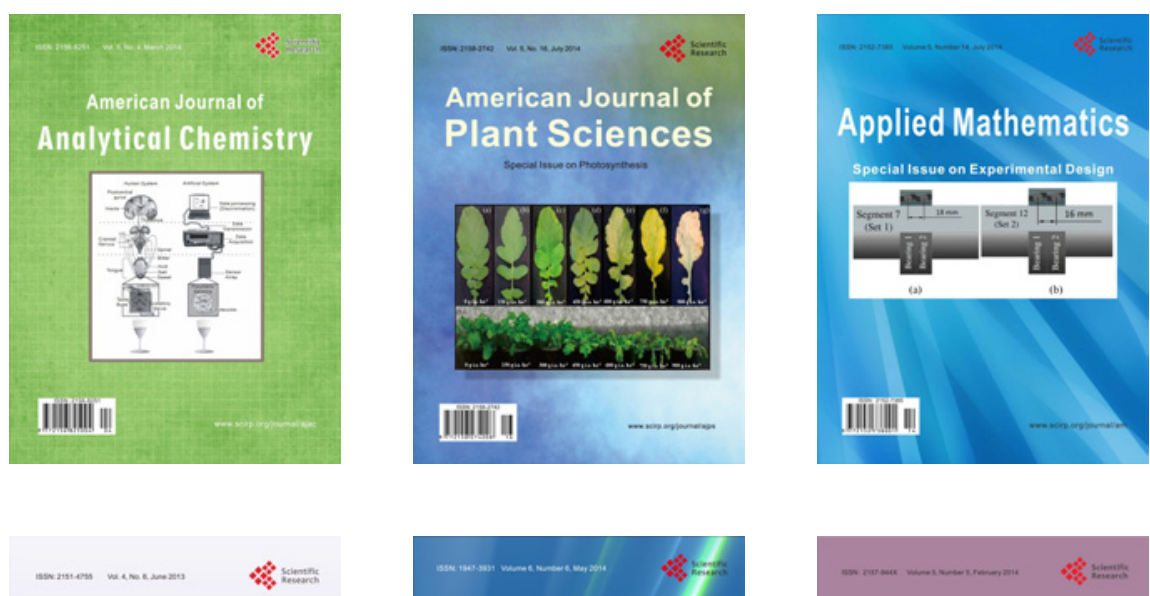

Creative Education
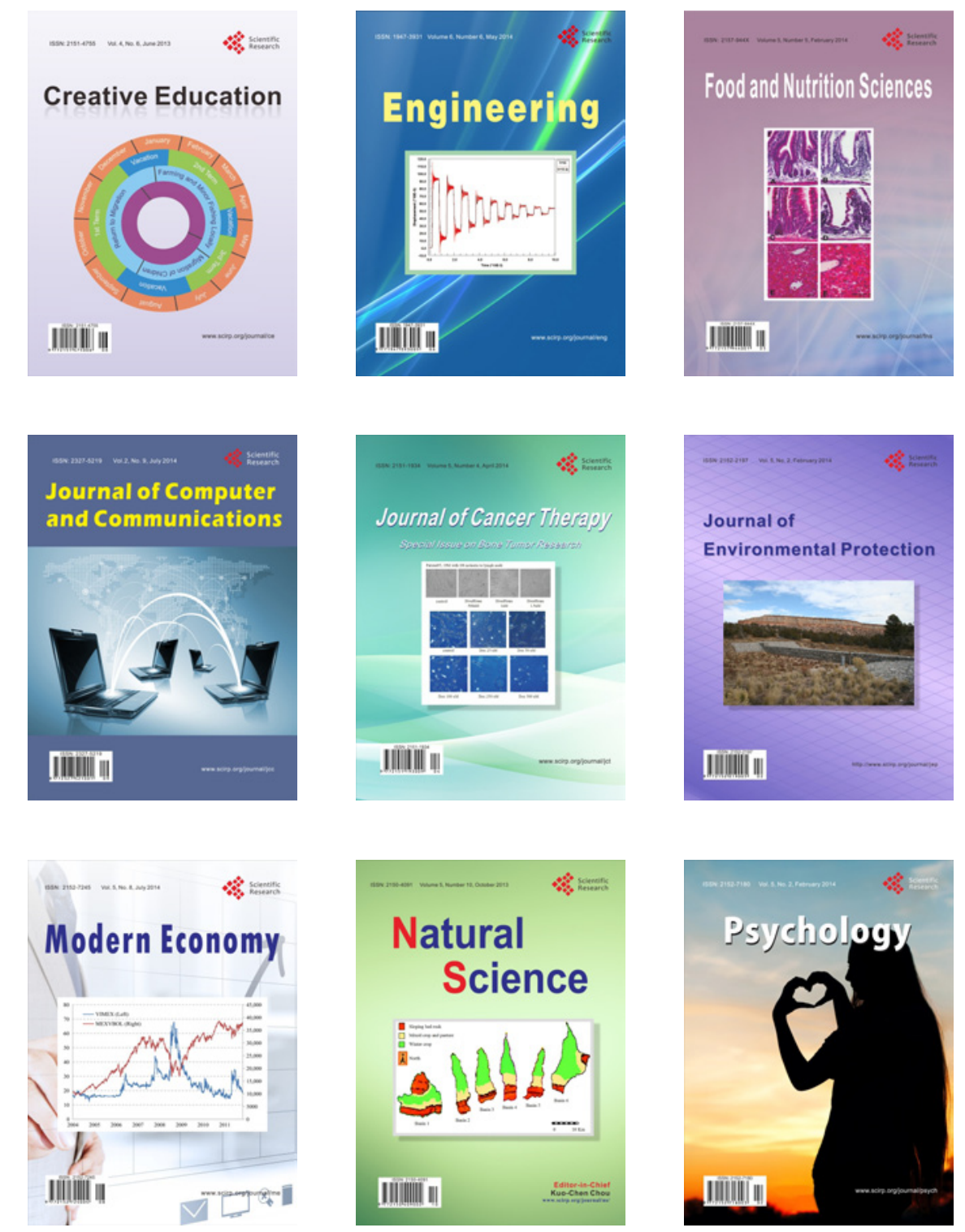